\title{
EXTREMES OF AGE DECREASE SURVIVAL AFTER LUNG TRANSPLANT
}

by

CARLI J. LEHR MD

Submitted in partial fulfillment of the requirements for the degree of Master of Science

Clinical Research Scholars Program

CASE WESTERN RESERVE UNIVERSITY

August 2018 


\title{
CASE WESTERN RESERVE UNIVERSITY SCHOOL OF GRADUATE STUDIES
}

\author{
We hereby approve the thesis/dissertation of \\ Carli Lehr \\ candidate for the degree of Master of Science
}

\author{
Committee Member \\ Maryam Valapour, MD, MPP \\ Committee Member \\ Reena Mehra, MD \\ Committee Member \\ Elliott Dasenbrook, MD, MS \\ Date of Defense \\ June 7, 2018
}

*We also certify that written approval has been obtained for any proprietary material contained therein. 


\section{TABLE OF CONTENTS}

List of Tables..........................................................

List of Figures..........................................................

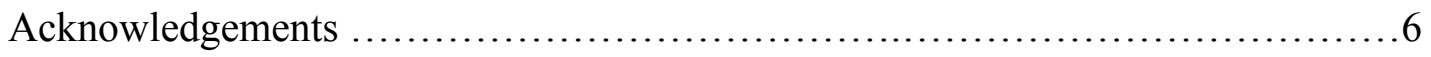

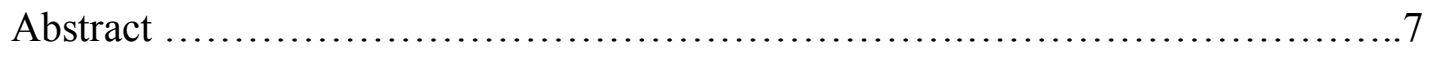

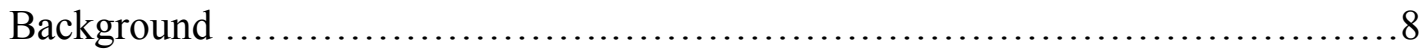

Methods ....................................................................

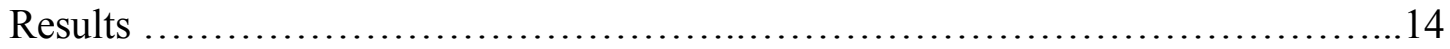

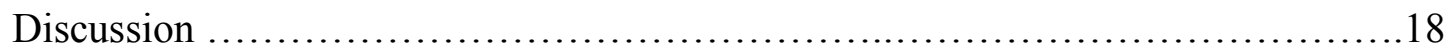

Limitations.......................................................... 22

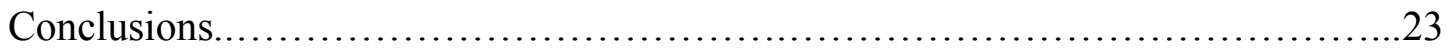

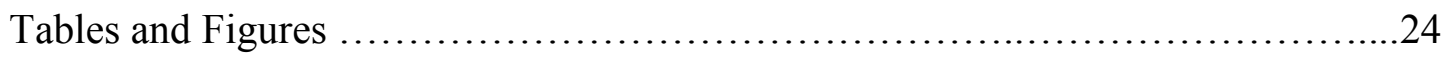

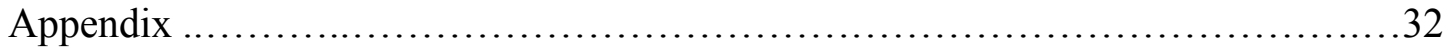

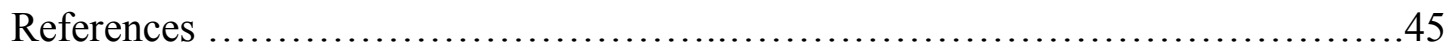




\section{LIST OF TABLES}

Table 1: Recipient characteristics by age group.................................24

Table 2: Incremental risk factors for death after lung transplant......................28 


\section{LIST OF FIGURES}

Figure 1: Kaplan Meier Survival by Age Group................................26

Figure 2: Risk-adjusted model of predicted survival by age among lung transplant

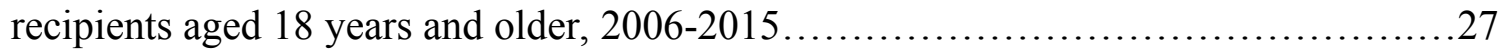

Figure 3: Variable importance measure boxplots for main and interaction terms...........31

Figure S1: Histogram of recipient age at transplant.................................33

Figure S2: Kaplan-Meier survival after lung transplant........................... 34

Figure S3: Percent distribution of cohort by age and diagnosis group................. 35

Figure S4: Phase decomposition and instantaneous risk of death after lung transplant...36

Figure S5: Variable importance measure (VIMP) for death ranked in decreasing order..37

Figure S6: VIMP for death ranked in decreasing order $(<30$ years $) \ldots \ldots \ldots \ldots \ldots \ldots . \ldots 38$

Figure S7: VIMP for death ranked in decreasing order $(30-55$ years $) \ldots \ldots \ldots \ldots \ldots . \ldots 39$

Figure S8: VIMP for death ranked in decreasing order $(>55$ years $) \ldots \ldots \ldots \ldots \ldots \ldots \ldots . \ldots 40$ 


\section{ACKNOWLEDGEMENTS}

Author Contributions: Dr. Lehr and Dr. Valapour had full access to all of the data in the study and takes responsibility for the integrity of the data and the accuracy of the data analysis.

Study concept and design: Lehr, Blackstone, Valapour

Acquisition of data: Thuita, Valapour

Analysis and interpretation of data: Lehr, Blackstone, Thuita, Valapour

Drafting of the manuscript: Lehr, Blackstone, Valapour

Critical revision of the manuscript for important intellectual content: Lehr, Blackstone, McCurry, Tsuang, Valapour

Statistical analysis: Lehr, Blackstone, Thuita, Valapour

Financial Disclosures: The authors do not have financial disclosures to report.

Funding/Support: Dr. Valapour is supported by grant funding from HRSA and the Cystic Fibrosis Foundation. Dr. Tsuang is supported by the American Society of Transplantation and National Institutes of Health. 
Extremes of Age Decrease Survival After Lung Transplant

Abstract

by

CARLI J. LEHR

The aim of this study was to determine impact of the age of lung transplant recipients on survival after lung transplant. We used data from the Scientific Registry of Transplant Recipients and studied 14,253 adult lung transplant recipients between January 1, 2006 and February 19, 2015. Survival was estimated using a non-proportional hazard model and random-survival forest methodology to examine risk-factors for death. Risk factors were obtained for the entire population and additional age-specific risk factors were identified for each age category. There were 1,098 (7.7\%) recipients $<30$ years, 4,201 $(29.5 \%) 30-55$ years, and 8,954 (62.8\%) $>55$ years of age. The youngest and oldest recipients experienced the lowest post-transplant survival. Risk factors for death for the entire population included extremes of age, higher creatinine, single lung transplant, hospitalization prior to transplant, and increased bilirubin. Age was the most significant risk factor for death at all time-points following transplant. 


\section{BACKGROUND}

Despite scientific advances and improvements in post-transplant care, long-term survival in lung transplantation has plateaued in the last decade with a 5-year survival rate of $55.6 \%{ }^{1}$. Another trend in the past decade has been the increasing age of lung transplant recipients aged $\geq 65$ years from $11.4 \%$ in 2006 to $29.3 \%$ in $2016^{2}$. As the age of transplant recipients has steadily increased, age has been implicated as a key factor contributing to static long-term survival in lung transplantation.

Multiple U.S. and international studies have demonstrated increased posttransplant mortality among older lung transplant recipients ${ }^{3-5}$ while others have not found a difference in mortality ${ }^{6,7}$. Generalizability of prior analyses is limited by center-specific practice variations, variable age classifications, and measurements spanning changes in lung allocation systems particularly in the U.S. which accounts for $>50 \%$ of all lung transplants performed worldwide. Disparate effects of age on survival have been reported in U.S. in analyses prior to implementation of the Lung Allocation Score (LAS) system in 2005 and after the LAS era ${ }^{8-10}$. The purpose of this study was to define the impact of age on outcomes following lung transplant in a modern cohort of patients. Our null hypothesis was that age does not impact long-term survival after lung transplant with long-term survival defined as survival greater than 5 years. 


\section{METHODS}

\section{Patients}

The study population consisted of 14,253 adult (aged $\geq 18$ years) primary lung transplant recipients between January 1, 2006 and February 19, 2015 to represent a post-LAS era contemporary patient cohort. Multi-organ recipients were excluded.

\section{Databases and Variables}

The study used data obtained from the Scientific Registry of Transplant Recipients (SRTR). The Organ Procurement and Transplantation Network (OPTN) provides data to the SRTR on all organ donors, waitlist candidates, and transplant recipients in the U.S. ${ }^{11}$. The data in the SRTR database is obtained from other databases including the Organ Procurement and Transplantation Network (OPTN), individual transplant programs, organ procurement organizations (OPOs), National Technical Information Service (NTIS) Death Master File, and histocompatibility laboratories. These databases are supplemented by the Centers for Medicare and Medicaid Services (CMS) database. The OPTN collects data through UNet, a secure internet-based data system. UNet includes data on all transplants performed since 1987 . SRTR receives monthly updates from the OPTN database and the NTIS Death Master file

Data was not directly collected by investigators at the Cleveland Clinic. Institutional Review Board (IRB) approval (protocol number 16-1639) was obtained through the Cleveland Clinic IRB. 
Variables utilized in parametric modelling included recipient, donor, and matched variables between the recipient and donor. LAS score at listing and the last recorded LAS prior to transplant were collected. The LAS is a normalized score ranging from 0 to 100 that is used to prioritize lung waitlist candidates ${ }^{12}$. An LAS score of 100 indicates the highest priority for access to lung transplant. To calculate the LAS, pulmonary diagnoses are characterized into four main groups based on survival probability and pathophysiology of the underlying disease. Diagnosis groups include group A, obstructive lung disease (e.g. chronic obstructive pulmonary disease (COPD)); group B, pulmonary vascular disease (e.g. idiopathic pulmonary arterial hypertension (IPAH)); group $\mathrm{C}$, cystic fibrosis $(\mathrm{CF})$ and immunodeficiency disorders; and group D, restrictive lung disease (e.g. idiopathic pulmonary fibrosis (IPF)). Recipient time to death and cause of death were obtained for mortality analysis. ${ }^{13}$

Completeness of data was assessed and multiple imputation using the Markov Chain Monte Carlo technique were used to estimate missing values by combining estimates from five separate models to yield final regression coefficient estimates and p-values ${ }^{14}$. Variables were required to have less than $30 \%$ missing values to be included in the analysis. All variables were included for analysis in both the parametric model and nonparametric random survival forest model and are listed in Supplementary Appendix 1.

\section{Endpoints}

The primary outcome is survival. All time was censored as of November 30, 2015. Median follow-up time for the group was 2.5 years with the $25^{\text {th }}$ and $75^{\text {th }}$ percentile at 1.0 
years and 4.9 years respectively. Twenty-five percent of the survivors were followed for greater than 5 years and $10 \%$ were followed for over 7 years. A total of 43,913 personyears were included for analysis. During this period, 425 patients underwent a lung retransplant. They remained in the analysis and were not censored at re-transplant. Postoperatively, lung transplant recipients are followed at a minimum at 6 months, 1 year, and annually thereafter and this data is shared with OPTN. The OPTN requires transplant programs to follow transplant patients until 2 years post-transplant. Death data was obtained by composite data provided by the NTIS Death Master File in addition to voluntary submission of death data from transplant programs to OPTN.

Secondary objectives included assessment of variables associated with an increased risk of death after lung transplant. Based on preliminary data analysis, there were two distinct phases for risk of death after lung transplant (Figure S4a, S4b). These occurred within 3 months and beyond 3 years post-transplant. Based on this observation, risk factors were assessed for association with cumulative risk of death after transplant and sub-set to early $(<3$ month) and late ( $>3$ years) post-transplant to gain further understanding of divergent risk factors by time.

\section{Statistical Analysis}

Kaplan-Meier ${ }^{15}$, non-proportional hazard , and non-parametric random survival forest (RSF) analyses ${ }^{16,17}$ were used to analyze the impact of age on survival after lung transplant. Data were censored at death or the end of follow-up (November 30, 2015). Descriptive statistics were used to summarize the data. The Wilcoxon rank sum test was 
used to compare continuous variables while Chi-square or Fisher's exact tests were used for categorical variables. Bootstrap aggregation was utilized in multivariable models to accommodate for variables with dissimilar distributions. A parametric method was used to resolve the number of phases of instantaneous risk of death ${ }^{18}$.

Variables were selected via bootstrap bagging methodology ${ }^{19}$. Continuous variables were rescaled as necessary to meet linearity assumptions of models. Transformations include squared, logarithmic, inverse, inverse squared, and exponentials. These transformations were performed on the original variables (Supplementary appendix 1) and were integrated into a bootstrap and aggregation (bagging) process. The most commonly appearing transformation was chosen for inclusion in the final multivariable model. The bootstrap sampling was performed by random sampling of cases with replacement with an average of $1 / 3$ of patients not chosen and some cases chosen more than once. The bootstrap sample was analyzed by an automated forward stepwise selection algorithm. Variables were considered if their $\mathrm{p}$ value was $<0.07$ and retained if $\mathrm{p}<0.05$. The sampling and automated selection algorithm were repeated 1000 times and the number of times a variable appeared in 1000 analyses was taken as a measure of reliability for the signal of that variable. The interpretation is that for variables that occurred in $50 \%$ of models, or in 500 of 1000 iterations, there is a $50 \%$ chance that the variable is statistically significant at a $\mathrm{p}<0.05$. As the reliability percentage increases, so does the likelihood that a variable is statistically significant within the parametric model. RSF is a non-parametric method that was used in concert with traditional parametric modelling. In contrast to traditional modelling strategies, RSF utilizes all variables to 
predict the outcome. The robustness of this technique is that linearity is not required and it improves the accuracy of the model by fitting numerous trees in an effort to stabilize the estimates of the model. RSF methodology uses both the variable importance measure (VIMP) and minimal depth ${ }^{17,20}$. In this method, bootstrap sampling is used and $36.8 \%$ of observations are left out in each iteration. These out of bag samples (36.8\% of the data) are then filtered to a tree to predict outcomes. Variables are selected by taking the square root of the co-variables examined $(\mathrm{n}=96)$ to build a tree from the bootstrap sample, and a forest of approximately 500 trees were created. The variables are then permuted to produce noise in the sample. The measure of VIMP is the difference between the out of bag prediction error before and after a permutation. RSF uses the VIMP to assess the effect of variables on forest prediction of the outcome with a larger VIMP value indicating greater impact. A VIMP value near zero indicates that a variable has no predictive value on the outcome and negative values indicate that the variable harms the ability to predict the outcome. To address possible confounders, VIMP interactions between age and additional variables were analyzed (Figure 3). Variables in the RSF method were imputed via the adaptive forest imputation method ${ }^{16}$. RSF methodology was used to validate parametric findings while avoiding statistical assumptions of traditionally parametric models, maximize sensitivity to variable interactions, and assess linear and non-linear relationships with survival.

Age was assessed as a continuous variable in multivariable mortality analysis which accounted for all available donor, recipient, and paired donor and recipient variables (Table 2). Based on the distribution of age versus predicted survival over time, divergent 
mortality trends arose in the younger, mid-aged, and older patients. Given these findings, age was also analyzed as a categorical variable with sub-groups of $<30,30-55$, and $>55$ years of age. Analysis was performed using SAS statistical software (SAS v9.1 (C) 2004, SAS Institute Inc., Cary, NC) and R version 3.0.1 ${ }^{21}$. RESULTS

\section{Patient Characteristics}

The cohort consisted of 14,253 lung transplant recipients with a median age of 59 years with the distribution skewed towards older age (Figure S1). There were 1,098 (7.7\%) recipients $<30,4,201(29.5 \%) 30-55$, and $8,954(62.8 \%)>55$ years of age. Female recipients comprised $52 \%$ of those $<30,47 \%$ of those $30-55$, and $35 \%$ of those $>55$ years of age (Table 1). The most prevalent form of insurance in each group was private insurance. Among those with public insurance, recipients $<30$ years of age had the highest proportion of Medicaid, a form of U.S. government insurance that provides coverage for disabled and low-income individuals.

The proportion of recipients in each diagnosis group varied by age (Figure S3).

Recipients in group $\mathrm{C}$ were the youngest and those in groups $\mathrm{A}$ and $\mathrm{D}$ the oldest. Cystic fibrosis was the most common diagnosis for transplant among those $<30$ years of age. Candidates with IPF received the most transplants (51.2\%), followed by those with COPD (31.6\%), cystic fibrosis (12.3\%), and pulmonary hypertension (4.9\%). Over the decade of data collection, the average recipient age at transplant increased across all diagnosis groups with the average age increasing most for those with COPD and IPF. 
The recipients in the youngest age group ( $<30$ years) had the greatest level of disability, highest severity of illness, and most frequent utilization of circulatory and ventilatory support (Table 1). Although mean LAS at listing was not statistically different among age groups, mean LAS at transplant was highest in the youngest age group, $49 \pm 18.4$, and lowest in the oldest age group ( $>55$ years) at $46.2 \pm 16.9$ (Table 1). Younger recipients had increased utilization of pre-transplant extra-corporeal membrane oxygenation (ECMO) and mechanical ventilation (18.8\%) compared to those in mid-age, range 30-55 years $(11.8 \%)$, and those $>55$ years $(6.2 \%)$. The youngest age group had the lowest body mass index (BMI) and highest proportion of disability as measured by Karnofsky Performance Status Scale (KS) ${ }^{22}$ compared to the other age groups.

\section{Risk Factors for Early and Late Death}

The mortality rate is highest early after transplant and then rises again late after transplant (Figure S4a, S4b). Early death was defined as death in less than 3 months and a late death was defined as $>3$ years posttransplant. Since the mortality rate differed with time from transplant, independent analysis of the two distinct phases was performed in addition to a composite survival analysis. Age was a risk factor for both early and late death.

Additionally, high pre-transplant bilirubin, bidirectional waitlist time, and shorter ischemic time were risk factors for both early and late death. Waitlist time showed bidirectional risk with a short waitlist time and longer ischemic time as risk factors for late death and a longer waitlist time and shorter ischemic times as risk factors for early death. 
Recipient-specific factors associated with an increased risk of early death include age, increased bilirubin, increased serum creatinine, smaller body-mass index (BMI), hypertension, pulmonary vascular disease, negative CMV IgG status, lower serum albumin, and lower cardiac output. Recipients with a history of prior cardiac surgery, dialysis, or those who required mechanical ventilation had an increased risk of early death. Lower percent predicted $\mathrm{FVC}, \mathrm{PCO}_{2}<30 \mathrm{mmHg}$ or $>90 \mathrm{mmHg}$, and shorter 6 minute walk distance (6MWD) were risk factors for early death. Earlier year of transplantation, hospitalization, with patients in an intensive care unit (ICU) experiencing worse survival, were risk factors for early death. Donor-specific factors associated with worse early survival include a larger size donor, greater ratio of recipient weight to donor weight, diabetic donor, and CMV sero-positivity of the donor.

Recipient-specific factors associated with an increased risk for late death include age, a lower education level and public insurance (Medicare/Medicaid), and lower education status. The category with the worst survival was no education/grade school, with sequential improvement in survival as education increased. Bilateral lung transplant recipients had a lower risk of late death compared to single lung transplants with right sided transplants having a lower risk of late death compared to left. A higher total number of human leukocyte antigen (HLA) mismatches and increased donor age were risk factors for worse late survival. 


\section{Association of Survival with Age}

Age was a significant risk factor for death at all time points and the magnitude of its effect became more evident as time from transplant increased (Figures 1, 2). Recipients in the youngest and oldest groups had worse survival compared to mid-age patients. The 1-year predicted survival was $93.9 \%$ for a 20 -year-old, $96.1 \%$ for a 45 -year-old, and $92.8 \%$ for a 65 -year-old recipient; five-year predicted survival for the same age groups was $64.5 \%, 81.2 \%$, and $71.5 \%$ respectively (Table 2 , Figure 2 ). Both parametric and nonparametric modeling identified that age was the most reliable and important predictor for post-transplant survival. Its VIMP value was over two times greater than the next highest variables of creatinine and double lung transplant. The interaction between age and risk factors for death were analyzed, demonstrating an increase in VIMP across variables, suggesting that the addition of age strengthens the precision of the model (Figure 3, Figure S5). RSF methodology across all ages identified the five most important factors for death by decreasing magnitude as being younger and older in age, higher creatinine, single lung transplant, hospitalization prior to transplant, and higher total bilirubin (Figure S5).

To determine whether risk factors for death differed by age, we analyzed our cohort by age groups, $<30,30-55$, and $>55$ years of age (Figure 1, Table 1). For those aged $<30$ years, elevated bilirubin, government insurance, lower education, longer waiting time, and higher creatinine were the most important predictors of mortality (Figure S6). In those aged 30-55 years, higher creatinine, diagnosis groups other than cystic fibrosis, black donor race, lower and higher BMI, and disabled functional status were most 
important (Figure S7). In those aged $>55$ years, ICU hospitalization, higher creatinine, left lung transplant, elevated bilirubin, and lower and higher ratio of donor to recipient predicted total lung capacity were the most important predictors of mortality (Figure S8).

\section{DISCUSSION}

\section{Principal Findings}

Among adult lung transplant recipients, age is the most reliable risk factor and most important predictor of death at all time points after transplant, with the oldest and youngest experiencing the worst survival. The effect of age on survival becomes stronger as time from transplant increases. Risk factors for death also differ by age; medical factors are important in survival across all age groups, but social determinants of health play a prominent role among those aged $<30$ years.

\section{Survival and Age in Context}

Prior studies addressing mortality among older recipients after lung transplant have focused on the effect of advancing age and procedure type among diagnoses. However, those studies included earlier cohorts, defined age as a categorical variable, or reported unadjusted registry data. Similar to our findings, the 2016 International Society for Heart and Lung Transplantation (ISHLT) registry reported that the risk of 1-year posttransplant mortality rose at age $55^{1}$ and multiple studies demonstrated that older recipients, $>60$ years ${ }^{4},>70$ years ${ }^{8}$, and $>75$ years ${ }^{9}$ of age had worse survival than younger recipients. In contrast, other studies showed that recipients, $>60^{6,7},>65^{5,7}$, and $>70$ years of age ${ }^{10,23}$ can experience equivalent survival to those who are younger. 
The effect of procedure type, single versus bilateral lung transplant, in older patients had variable effects on survival across ages, diagnoses, and transplant eras ${ }^{24-29}$.

Our study has resolved limitations of prior studies by utilizing the largest modern U.S. cohort of transplant candidates and recipients, performing a survival analysis that adjusts for all available recipient and donor variables in the SRTR registry including procedure type, and studying age as a continuous variable. The role of age in survival has been published in the ISHLT annual registry reports ${ }^{1,30}$, representing a heterogenous patient population with data from multiple countries of which the U.S. compromises $51 \%$, variable practice patterns, and diverse allocation systems. Our work is the largest study of the impact of age as a continuous variable on survival that uses the authoritative U.S. transplant registry including only recipients from the LAS era.

While the finding of decreased survival in older recipients was expected, the observation of decreased survival in younger adult recipients was less expected. However, poor survival in the pediatric and adolescent populations has been previously described. A recent study using the ISHLT registry demonstrated that adolescents aged 14-19 years have worse survival compared to those $<14$ and $>19$ years ${ }^{31}$. Stephenson et al demonstrated decreased survival in both pediatric and older adult recipients with $\mathrm{CF}^{32}$. Studies of pediatric CF patients similarly did not find survival benefit from transplant in the pre-LAS era ${ }^{33}$ and showed decreased 3-year survival in the LAS era ${ }^{34}$. In our study, this trend of lower survival persisted in younger adults across diagnosis groups in the 
current transplant era; however, $82 \%$ of recipients in the youngest transplant cohort carried a diagnosis of $\mathrm{CF}$.

Important contrasts existed between the youngest and oldest patients at listing and posttransplant. Several listing trends indicate that transplant programs accepted a higher degree of illness as the youngest patients' clinical condition deteriorated while awaiting transplant. The youngest required disproportionately higher use of life support and had greater disability. They also had a LAS similar to other age groups at initial listing, but had the highest LAS of any cohort by the end of the waiting time when they reached transplant. This difference in LAS between groups is meaningful because LAS scores for $50 \%$ of U.S. lung transplant candidates fall within a narrow range of only 15 points on a 100 point scale ${ }^{35}$.

Traditionally defined medical factors affected post-transplant mortality across all ages. For the youngest, additional risk factors like insurance status, education, and waiting time were important. Waiting time likely served as a surrogate for worsening clinical condition during the wait for a transplant. These findings support the observation that transplant physicians and programs alike are more apt to support younger patients' candidacy and allow for higher degree of illness in this population where they would consider a clinically similar older candidate too sick for transplant. It is possible that this practice is based on the clinical intuition that young patients can overcome a greater degree of illness than their older counterparts - an intuition that is not fully borne out in 
our analysis, or an ethical imperative to prefer our youngest in distribution of limited lifesaving societal resources.

\section{Ethical and Policy Implications}

Several ethical paradigms can be used to justify preferential access to organ transplant for younger adults. The "fair-innings" perspective provides useful guidance by arguing that every individual deserves to experience a full life and that societal resources should be expended to maximize this chance ${ }^{36}$. The "min-max" perspective requires maximizing the distribution of limited resources to those receiving minimum societal advantages. This approach would allow for preferential allocation of organs to younger patients who disproportionately occupy a lower socioeconomic status than their older counterparts and who will invariably experience a premature death.

The LAS system, as it applies to adults, stands in contrast to these ethical principles. It prioritizes measures of waitlist mortality, which disproportionately increases access for older adult candidates who inherently have a higher risk of death on the waiting list. A recent mandate imposed on U.S. policymakers to decrease geographic disparity in access to transplant may alter the current allocation system to further favor the oldest and sickest candidates unless post-transplant survival is given appropriate consideration ${ }^{37}$. 


\section{LIMITATIONS}

This study has limitations intrinsic to a large registry including lack of granularity in variables which may affect survival, missingness, and unmeasured period effects. We addressed the lack of data on ICU stay, days on mechanical ventilation or ECMO by adjusting for number of hospitalized days and utilization of mechanical ventilation or ECMO. While comorbidities such as diabetes, hypertension, and presence of cardiovascular disease were captured in the registry, other conditions such as the presence of gastroesophageal reflux or prior malignancy were not. Missingness of data was present in this registry and variables with $<30 \%$ missingness were included in initial models. All variables that were important predictors of mortality by VIMP had $\leq 10 \%$ missingness, however only one variable, education, had $10 \%$ missingness, with the next highest value of $2 \%$ for bilirubin.

To circumvent era effect and study a modern cohort, our analysis period began the year after implementation of the LAS system. However, in a study that spans a nine-year period, there are potential unmeasured period effects and variability in sub-groups over time. Although our main analysis was performed with age as a continuous variable, we also grouped age based on survival models to uncover age-specific targets for intervention. We caution these cut-points should not be used clinically or for allocation purposes. 


\section{CONCLUSIONS}

These results encompass the entire lung transplant experience of the United States in the LAS era and represent the largest study of risk factors for death after transplant in the U.S. ${ }^{12}$. The LAS system changed the behavior of transplant physicians by favoring candidates based on urgency rather than time spent on the waiting list making way for

lung transplant recipients that are increasingly older and sicker ${ }^{38}$. We show that among recipients, the youngest and oldest experience the worst survival though through divergent pathways.

Our findings suggest that clinicians should focus on evaluating medical comorbidities among older patients in order to optimally select candidates who can experience better survival. In the case of the youngest patients, we may have an opportunity to improve survival by designing interventions that specifically target the contribution of low socioeconomic status to their mortality. As U.S. policy alternatives that overemphasize waitlist mortality are being considered, the impact of long-term survival must be taken into account to ensure future gains in post-transplant survival. 


\section{TABLES AND FIGURES}

\section{Table 1: Recipient characteristics by age group}

Variables summarized with number and percentage for categorical variables and mean and standard deviation (SD) for continuous variables. BMI, body mass index; ECMO, extracorporeal membrane oxygenation; FVC, forced vital capacity; $\mathrm{FEV}_{1}$, forced expiratory volume in 1 second percent; KS, Karnofsky Performance Status Score; LAS, lung allocation score; 6MWD, six minute walk distance.

Diagnosis Group A, obstructive lung disease; Diagnosis Group B, pulmonary vascular disease; Diagnosis Group C, cystic fibrosis and immunodeficiency disorders; Diagnosis Group D, restrictive lung disease.

\begin{tabular}{|c|c|c|c|}
\hline Variable & $\begin{array}{c}\text { Age }<30 \\
\text { years }\end{array}$ & Age $30-55$ years & $\begin{array}{c}\text { Age }>55 \\
\text { years }\end{array}$ \\
\hline & \multicolumn{3}{|c|}{ Mean \pm SD or No. (\%) } \\
\hline Age at Transplant & $24.2 \pm 3.2$ & $46.3 \pm 7.3$ & $63.4 \pm 4.6$ \\
\hline Gender (female) & $568(52 \%)$ & $1981(47 \%)$ & $3168(35 \%)$ \\
\hline BMI at transplant $\left(\mathrm{kg} / \mathrm{m}^{2}\right)$ & $19.5 \pm 3.36$ & $24.7 \pm 4.89$ & $25.9 \pm 4.19$ \\
\hline \multicolumn{4}{|l|}{ Education } \\
\hline $\begin{array}{r}\text { None } \\
\text { Grade School } \\
\text { High School } \\
\text { College } \\
\text { Associate/Bachelor Degree } \\
\text { Graduate Degree }\end{array}$ & $\begin{array}{l}2(0.2) \\
13(1.3) \\
428(42) \\
370(36) \\
175(17) \\
37(3.6)\end{array}$ & $\begin{array}{l}6(0.2) \\
103(2.7) \\
1471(39) \\
1050(28) \\
853(23) \\
292(7.7)\end{array}$ & $\begin{array}{l}11(0.1) \\
254(3) \\
3139(39) \\
2056(25) \\
1672(21) \\
963(12)\end{array}$ \\
\hline \multicolumn{4}{|l|}{ Primary Diagnosis } \\
\hline $\begin{array}{l}\text { Group A } \\
\text { Group B } \\
\text { Group C } \\
\text { Group D }\end{array}$ & $\begin{array}{l}51(4.6) \\
51(4.6) \\
897(82) \\
99(9)\end{array}$ & $\begin{array}{l}1075(26) \\
379(9) \\
815(19) \\
1932(46)\end{array}$ & $\begin{array}{l}3372(38) \\
268(3) \\
44(0.49) \\
5270(59)\end{array}$ \\
\hline Pre-transplant tobacco use & $64(6)$ & $1963(48)$ & $6611(75)$ \\
\hline Chronic Steroid Use & $353(33)$ & $1951(48)$ & $4083(47)$ \\
\hline
\end{tabular}




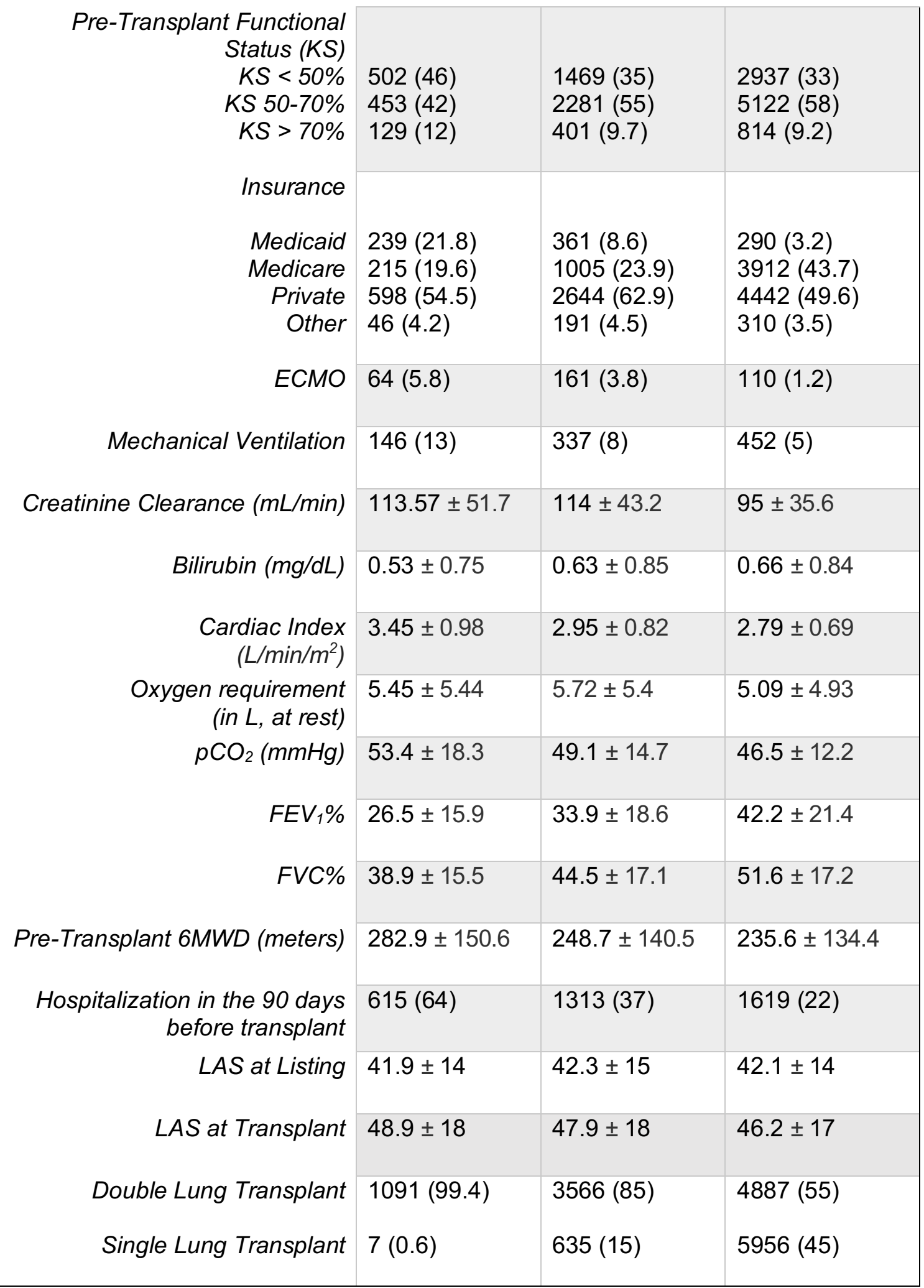




\section{Figure 1: Kaplan Meier Survival by Age Group}

Age $<30$ years (blue), Age 30-55 years (red), Age $>55$ years (green)

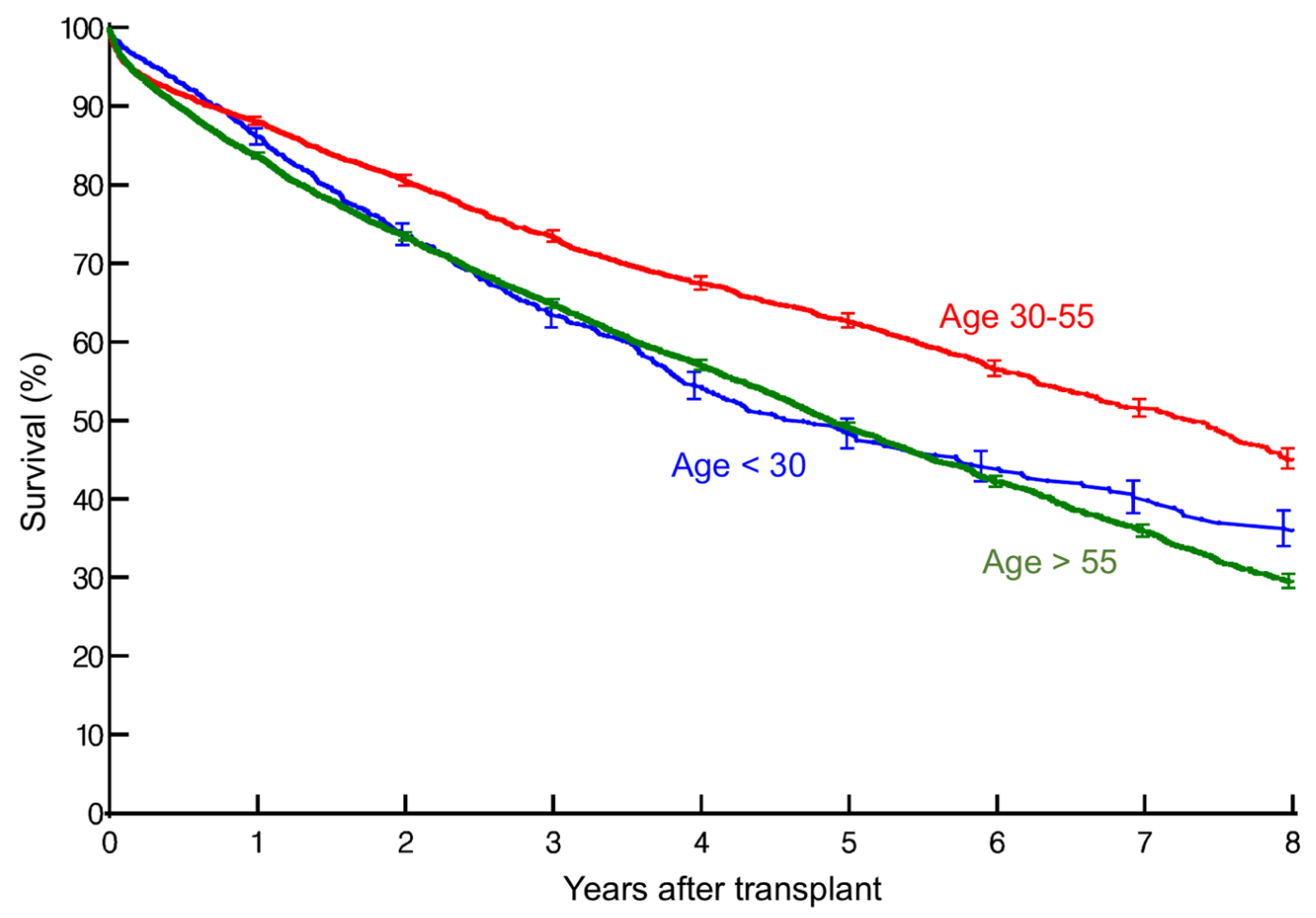

Patients at risk

\begin{tabular}{|l|l|l|l|l|l|l|l|l|l|}
\hline & 0 & $1 \mathrm{yr}$ & 2 yrs & $3 \mathrm{yrs}$ & 4 yrs & 5 yrs & 6 yrs & 7 yrs & 8 yrs \\
\hline$<30$ years & 1098 & 889 & 666 & 496 & 351 & 236 & 179 & 109 & 53 \\
\hline $30-55$ years & 4201 & 3473 & 2650 & 2045 & 1568 & 1182 & 774 & 522 & 277 \\
\hline$>55$ years & 8954 & 6788 & 4976 & 3670 & 2625 & 1815 & 1163 & 657 & 322 \\
\hline
\end{tabular}


Figure 2: Risk-adjusted model of predicted survival by age among lung transplant recipients aged 18 years and older, 2006-2015

Risk-adjusted survival after lung transplant according to recipient age. Solid lines represent parametric estimates with a $68 \%$ confidence limit with dashed lines. Model inputs included in supplementary appendix S2.

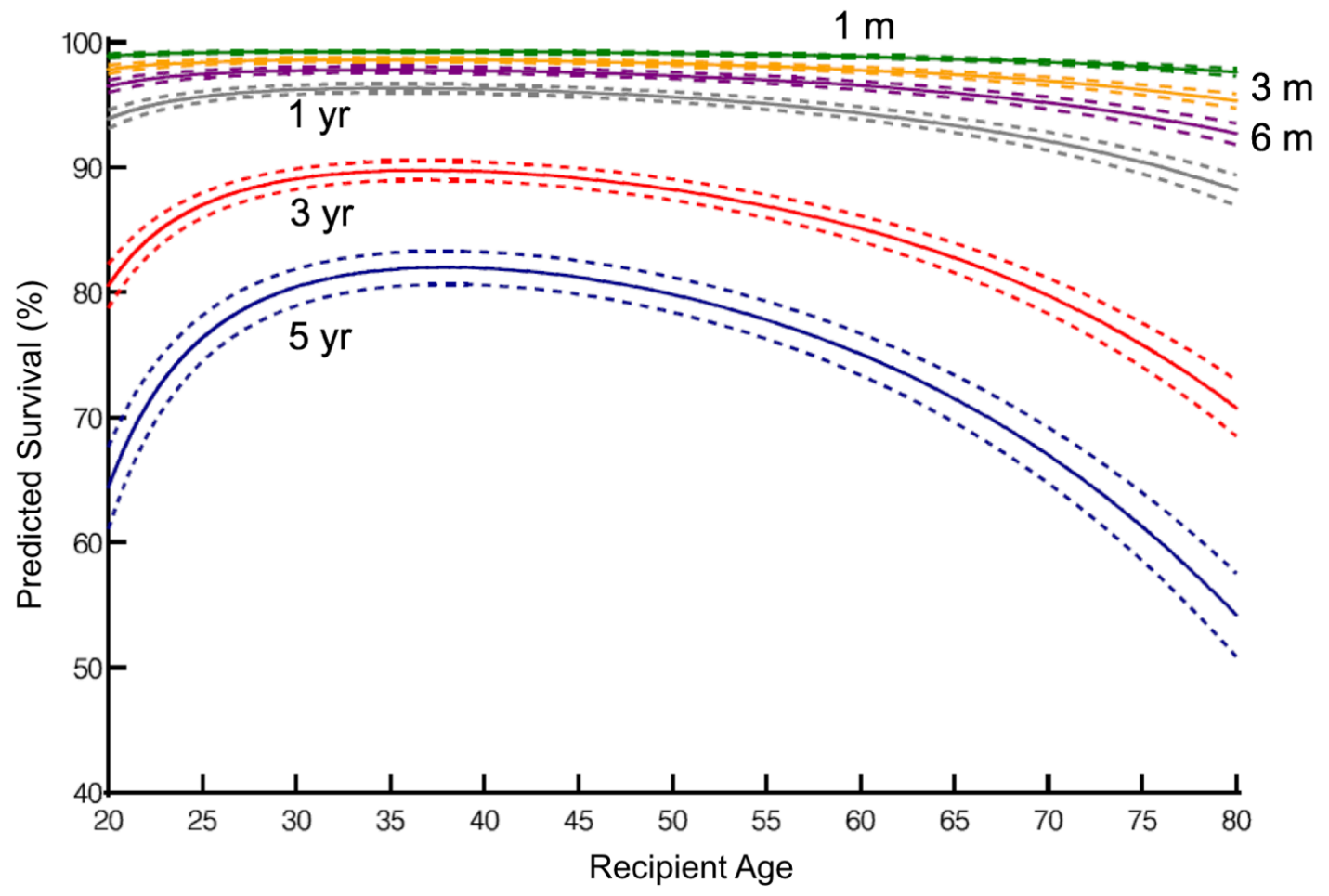


Table 2: Incremental risk factors for death after lung transplant

Reliability: Percentage of the time that variables occurred in 1000 bootstrapped models. Variable transformations (a-s) located in Supplementary Appendix S3.

\begin{tabular}{|c|c|c|c|}
\hline Variable & $\begin{array}{l}\text { Coefficient } \pm \\
\text { Standard Error }\end{array}$ & P-Value & $\begin{array}{c}\text { Reliability } \\
\text { (\%) }\end{array}$ \\
\hline \multicolumn{4}{|c|}{ Early Phase } \\
\hline \multicolumn{4}{|l|}{ Recipient Variables } \\
\hline \multicolumn{4}{|l|}{ Age } \\
\hline $\mathrm{Age}^{\mathrm{a}}$ & $0.735 \pm 0.074$ & $<0.001$ & 98 \\
\hline $\mathrm{Age}^{\mathrm{b}}$ & $0.161 \pm 0.033$ & $<0.001$ & 98 \\
\hline \multicolumn{4}{|l|}{ Body Mass Index(BMI) } \\
\hline $\mathrm{BMI}^{\mathrm{c}}$ & $1.88 \pm 0.71$ & 0.007 & 58 \\
\hline $\mathrm{BMI}^{\mathrm{d}}$ & $1.64 \pm 0.77$ & 0.03 & 58 \\
\hline Diagnosis: Pulmonary vascular & $0.331 \pm 0.084$ & $<0.001$ & 95 \\
\hline Recipient CMVIGG & $-0.123 \pm 0.041$ & 0.003 & 60 \\
\hline Prior cardiac surgery & $0.357 \pm 0.12$ & 0.03 & 63 \\
\hline Dialysis & $0.857 \pm 0.21$ & $<0.001$ & 88 \\
\hline Hypertension & $0.137 \pm 0.051$ & 0.008 & 55 \\
\hline Lower albumin & $-0.145 \pm 0.036$ & $<0.001$ & 96 \\
\hline \multicolumn{4}{|l|}{ Creatinine } \\
\hline Creatinine $^{\mathrm{e}}$ & $0.782 \pm 0.101$ & $<0.001$ & 83 \\
\hline Creatinine $^{f}$ & $0.375 \pm 0.068$ & $<0.001$ & 83 \\
\hline Higher total bilirubin & $0.098 \pm 0.015$ & $<0.001$ & 100 \\
\hline Lower cardiac output ${ }^{9}$ & $0.257 \pm 0.042$ & $<0.001$ & 70 \\
\hline Lower \% predicted Transplant FVC & $0.223 \pm 0.047$ & $<0.001$ & 81 \\
\hline \multicolumn{4}{|l|}{$\mathrm{PCO}_{2}$} \\
\hline $\mathrm{PCO} 2$ & $-0.018 \pm 0.007$ & 0.01 & 81 \\
\hline $\mathrm{PCO}^{\mathrm{i}}$ & $0.0002 \pm .00005$ & 0.03 & 81 \\
\hline Shorter walk distance ${ }^{j}$ & $-0.076 \pm 0.021$ & $<0.001$ & 98 \\
\hline Ventilation & $0.213 \pm 0.075$ & 0.004 & 63 \\
\hline \multicolumn{4}{|l|}{$\begin{array}{l}\text { Functional status (ref: disabled } \\
<50 \% K S \text { ) }\end{array}$} \\
\hline Unable $(50-70 \% \mathrm{KS})$ & $-0.317 \pm 0.047$ & $<0.001$ & 100 \\
\hline
\end{tabular}




\begin{tabular}{|c|c|c|c|}
\hline Able $(>=70 \% \mathrm{KS})$ & $-0.629 \pm 0.089$ & $<0.001$ & 100 \\
\hline Non-Hospitalized & $-0.361 \pm 0.064$ & $<0.001$ & 99 \\
\hline Shorter pre-operative hospital stayk & $-0.716 \pm 0.027$ & 0.007 & 88 \\
\hline Longer waitlist time' & $0.062 \pm 0.013$ & $<0.001$ & 99 \\
\hline Longer ischemic time(hours) $^{\mathrm{m}}$ & $0.084 \pm 0.024$ & $<0.001$ & 85 \\
\hline Earlier year of transplant & $-0.050 \pm 0.008$ & $<0.001$ & 100 \\
\hline \multicolumn{4}{|l|}{ Donor Variables } \\
\hline Donor race black & $0.183 \pm 0.048$ & $<0.001$ & 78 \\
\hline Donor larger $\mathrm{BMI}^{\mathrm{n}}$ & $0.498 \pm 0.139$ & $<0.001$ & 73 \\
\hline Donor diabetic & $0.229 \pm 0.073$ & $<0.002$ & 60 \\
\hline Donor anti CMV & $0.210 \pm 0.044$ & $<0.001$ & 91 \\
\hline \multicolumn{4}{|l|}{ Matched Recipient/Donor Variables } \\
\hline Weight ratio recipient/donor ${ }^{\circ}$ & $0.236 \pm 0.039$ & $<0.001$ & 91 \\
\hline \multicolumn{4}{|l|}{ Late Phase } \\
\hline \multicolumn{4}{|l|}{ Recipient Variables } \\
\hline \multicolumn{4}{|l|}{ Age } \\
\hline $\operatorname{Age}^{\mathrm{b}}$ & $0.383 \pm 0.033$ & $<0.001$ & 100 \\
\hline $\operatorname{Age}^{p}$ & $0.512 \pm 0.065$ & $<0.001$ & 100 \\
\hline Education lower level & $-0.065 \pm 0.023$ & 0.005 & 88 \\
\hline Diagnosis: Sarcoidosis & $-0.320 \pm 0.016$ & 0.004 & 50 \\
\hline Medicaid & $0.492 \pm 0.085$ & $<0.001$ & 100 \\
\hline Medicare & $0.167 \pm 0.052$ & 0.001 & 100 \\
\hline Higher total bilirubin ${ }^{q}$ & $-0.081 \pm 0.038$ & 0.03 & 66 \\
\hline $\begin{array}{l}\text { Listing functional status Able } \\
(>=70 \% \mathrm{KS})\end{array}$ & $-0.154 \pm 0.068$ & 0.023 & 61 \\
\hline Shorter waitlist time & $-0.109 \pm 0.029$ & $<0.001$ & 97 \\
\hline Shorter ischemic time ${ }^{r}$ & $0.143 \pm 0.049$ & 0.008 & 69 \\
\hline Double lung transplant & $-0.471 \pm 0.062$ & $<0.001$ & 100 \\
\hline Single right sided lung transplant & $-0.152 \pm 0.069$ & 0.03 & 51 \\
\hline Donor Variables & & & \\
\hline
\end{tabular}




\begin{tabular}{|l|l|l|l}
\hline Older donor age & $0.146 \pm 0.054$ & 0.006 & 70
\end{tabular}

Matched Recipient/Donor Variables

\begin{tabular}{|l|l|l|l} 
Higher number of HLA mismatches & $0.062 \pm 0.025$ & 0.02 & 56
\end{tabular}


Figure 3: Variable importance measure (VIMP) boxplots for main and interaction terms

Interaction terms were analyzed by random survival forest (RSF) methodology to address interactions with the effect of age. The addition of age increases the VIMP measure for each variable, indicating increased precision of the model for estimating the outcome of death. The VIMP value for age alone is found in the last row of the figure for reference.

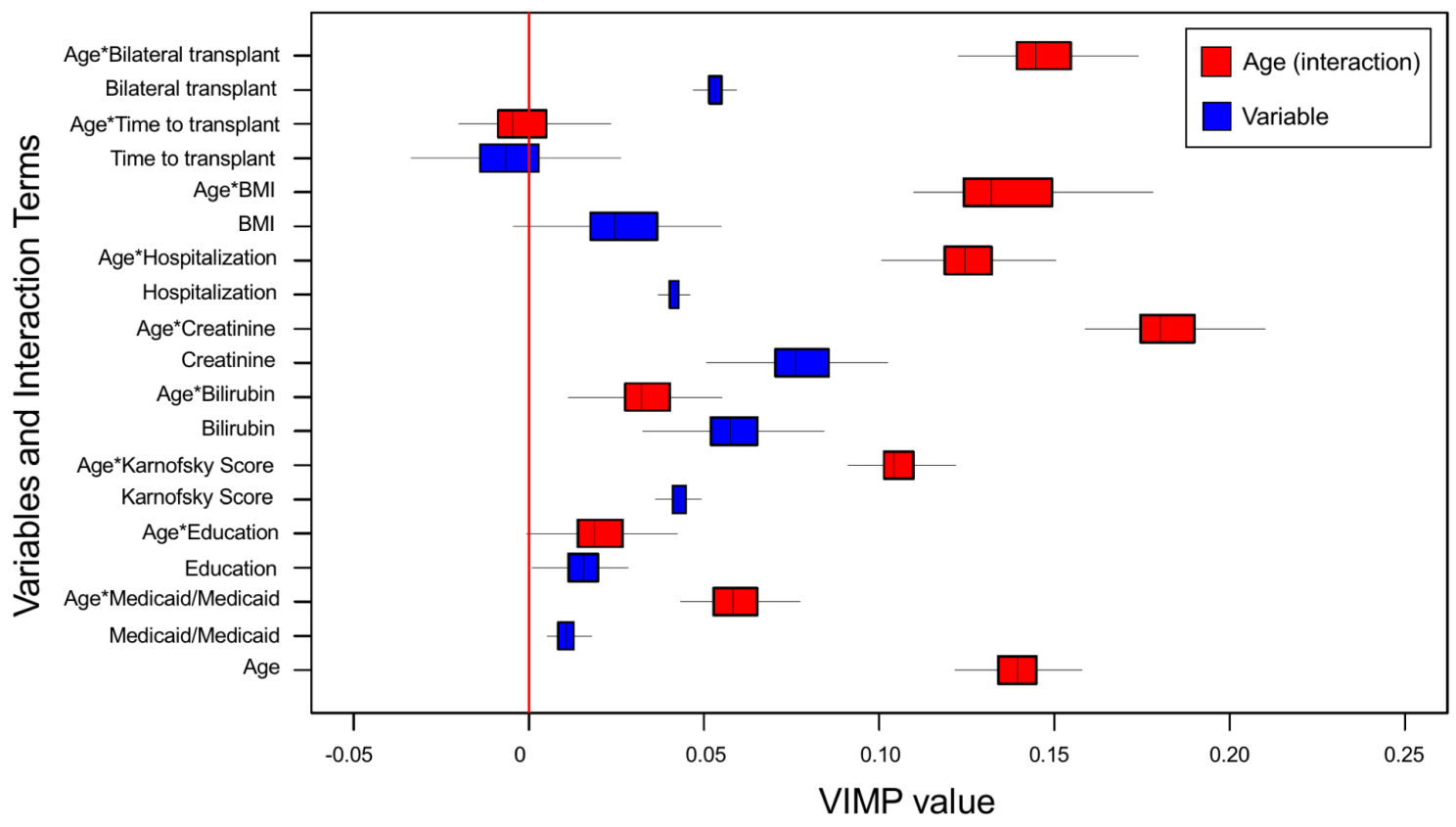




\section{APPENDIX}

Table of Contents:

Figure S1: Histogram of recipient age at transplant

Figure S2: Kaplan-Meier survival after lung transplant

Figure S3: Percent distribution of cohort by age and diagnosis group

Figure S4: Phase decomposition and instantaneous risk of death after lung transplant

Figure S5: Variable importance measure (VIMP) for death ranked in decreasing order

Figure S6: VIMP for death ranked in decreasing order $(<30$ years $)$

Figure S7: VIMP for death ranked in decreasing order ( 30 - 55 years)

Figure S8: VIMP for death ranked in decreasing order ( $>55$ years)

Supplementary Appendix S1: Variables considered in multivariable analyses

Supplementary Appendix S2: Figure 2 model inputs

Supplementary Appendix S3: Variable transformations for Table 2 (a-s) 
Figure S1: Histogram of recipient age at transplant

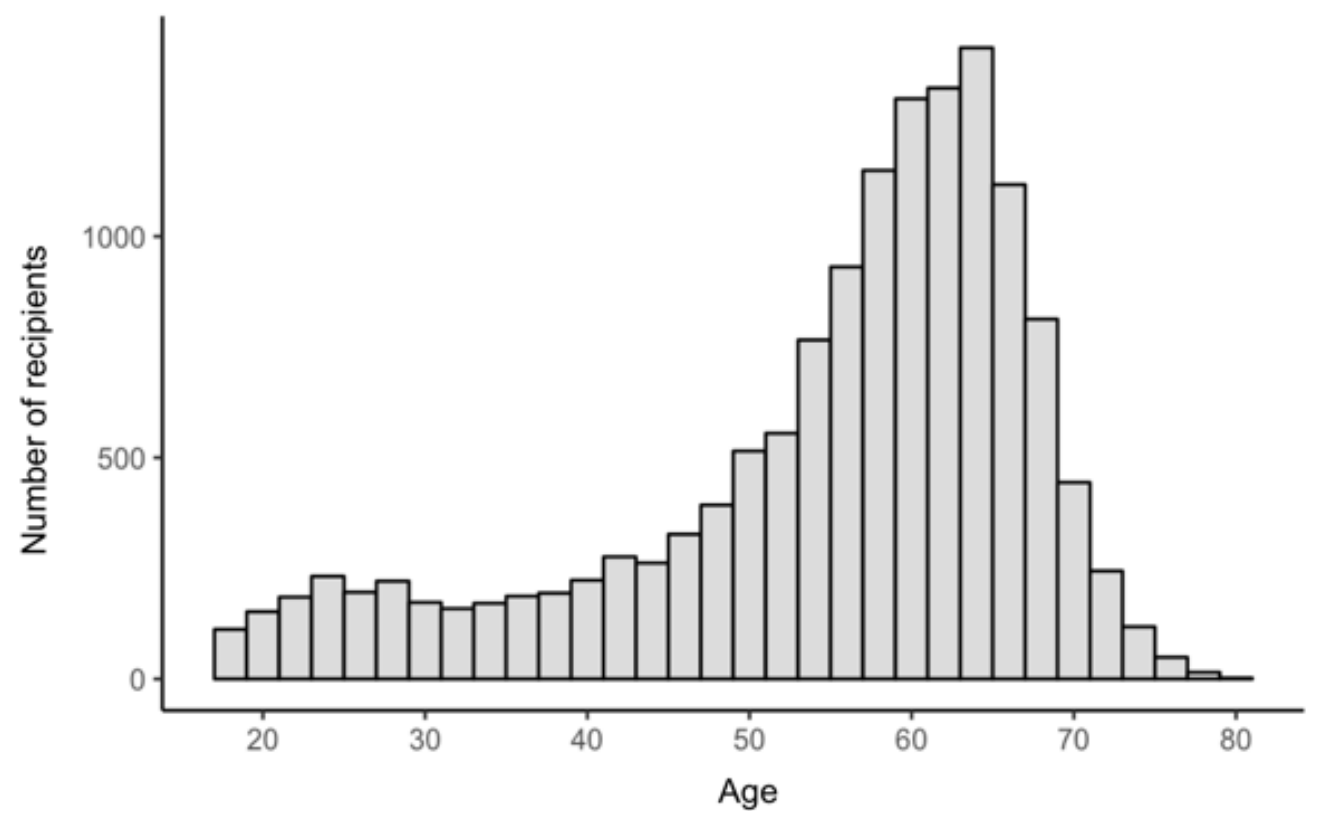


Figure S2: Kaplan-Meier Survival Estimates After Lung Transplant

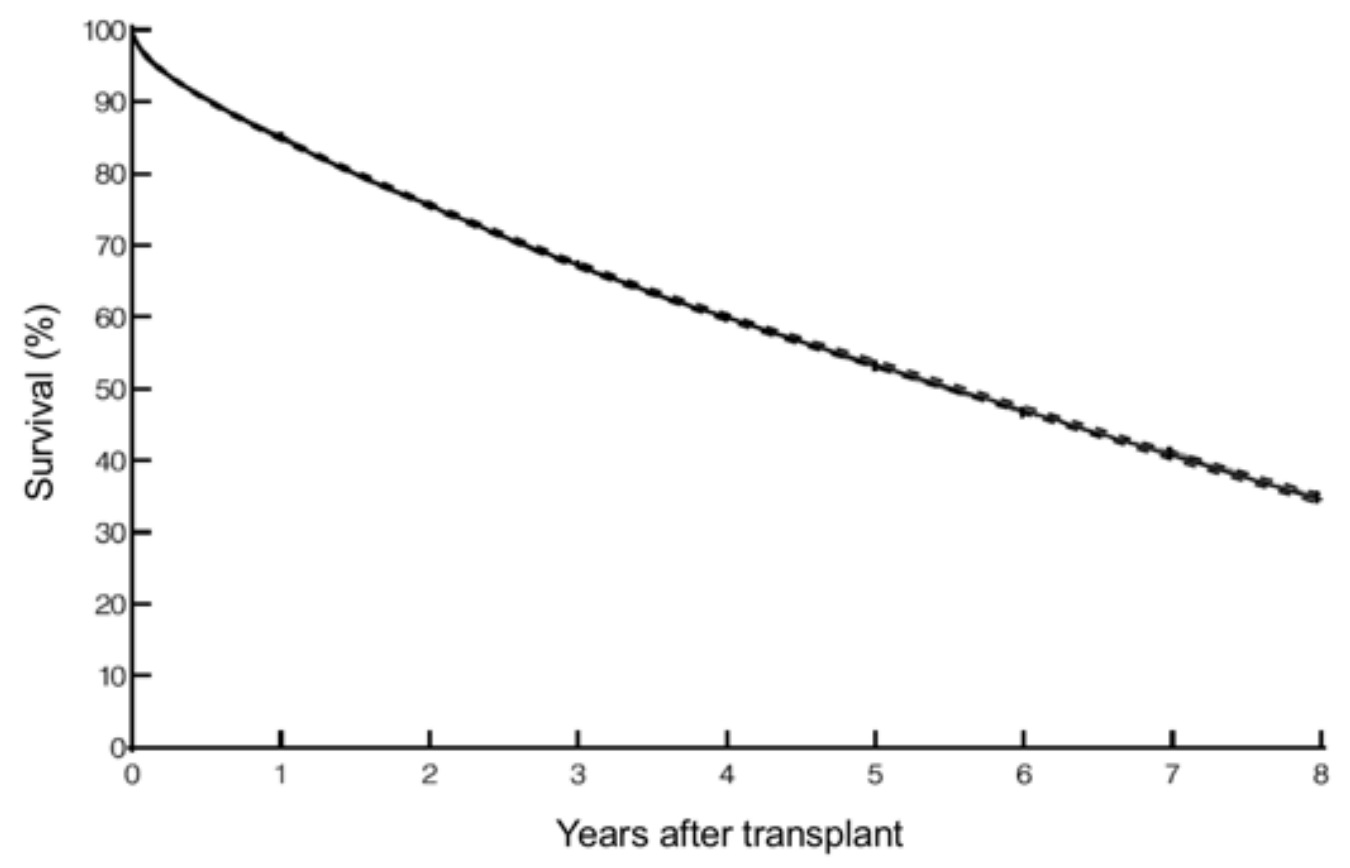

Patients at risk

\begin{tabular}{|l|l|l|l|l|l|l|l|l|l|}
\hline Years & 0 & 1 & 2 & 3 & 4 & 5 & 6 & 7 & 8 \\
\hline$\#$ & 14253 & 11070 & 8281 & 6199 & 4528 & 3218 & 2095 & 1260 & 646 \\
\hline
\end{tabular}


Figure S3: Percent distribution of the cohort by age and diagnosis group

Group A - Obstructive lung disease, Group B - Pulmonary vascular disease, Group C Cystic lung disease, Group D - Restrictive lung disease

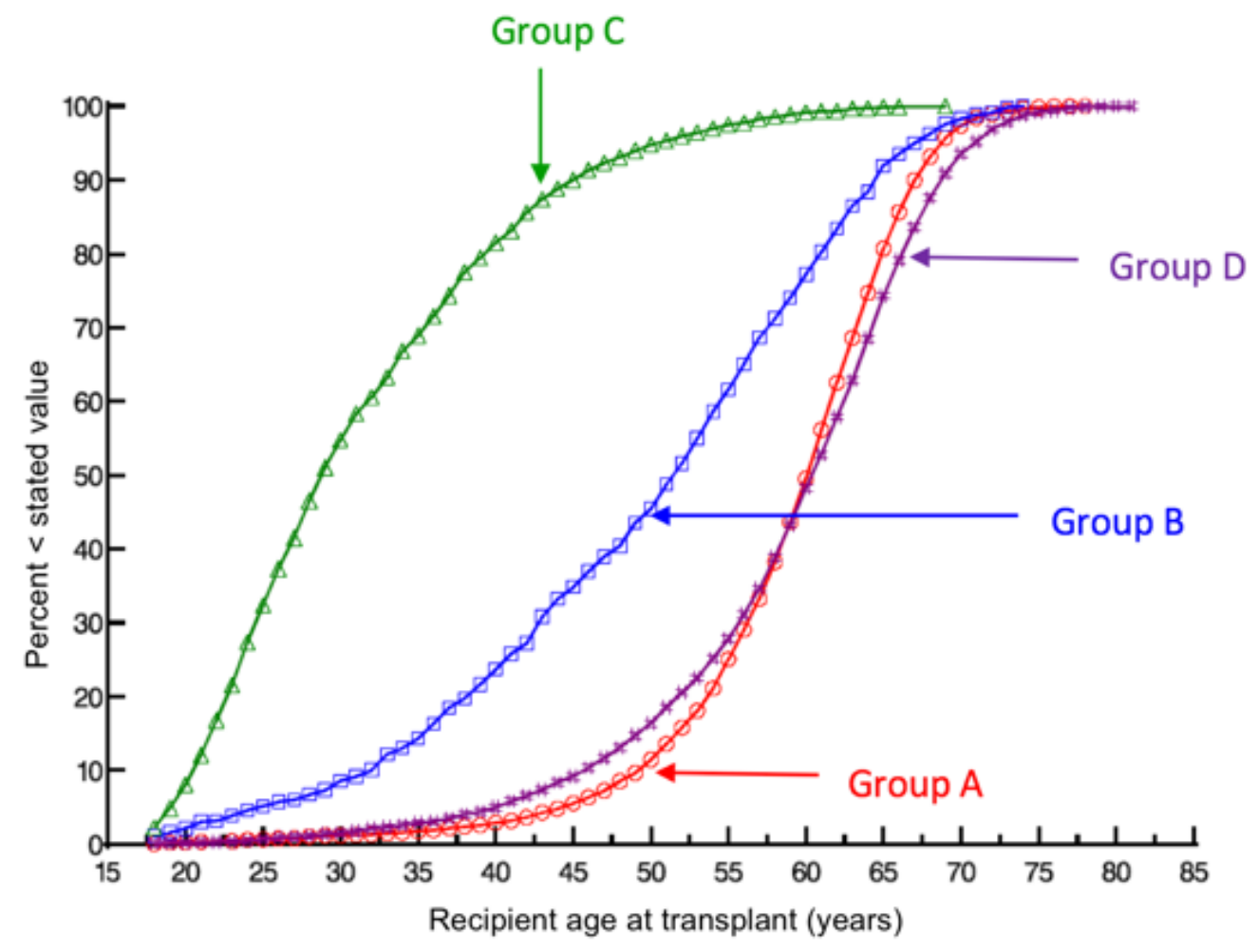


Figure S4a. Decomposition of phases for risk of death (early and late)

Figure S4b. Instantaneous risk of death (hazard function) after lung transplantation. Solid lines represent parametric estimates enclosed within a $68 \%$ confidence interval.

a.

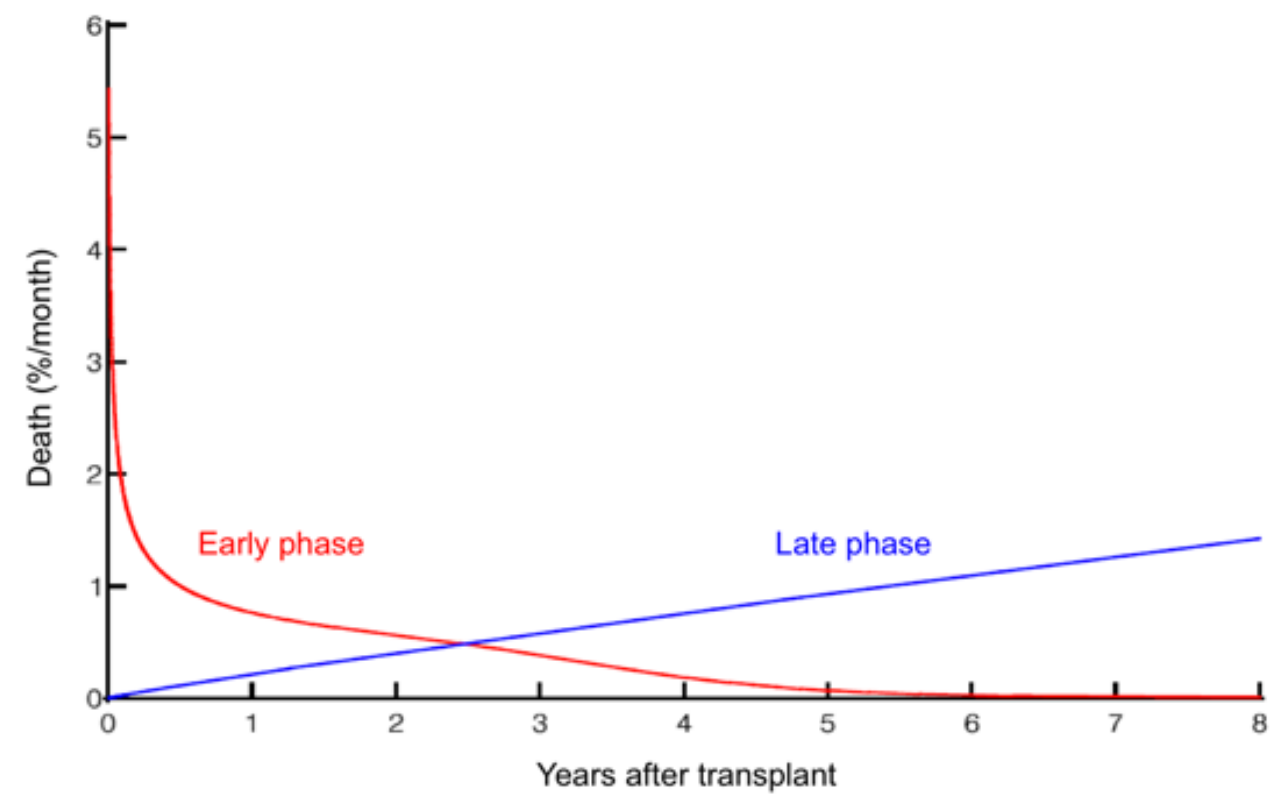

b.

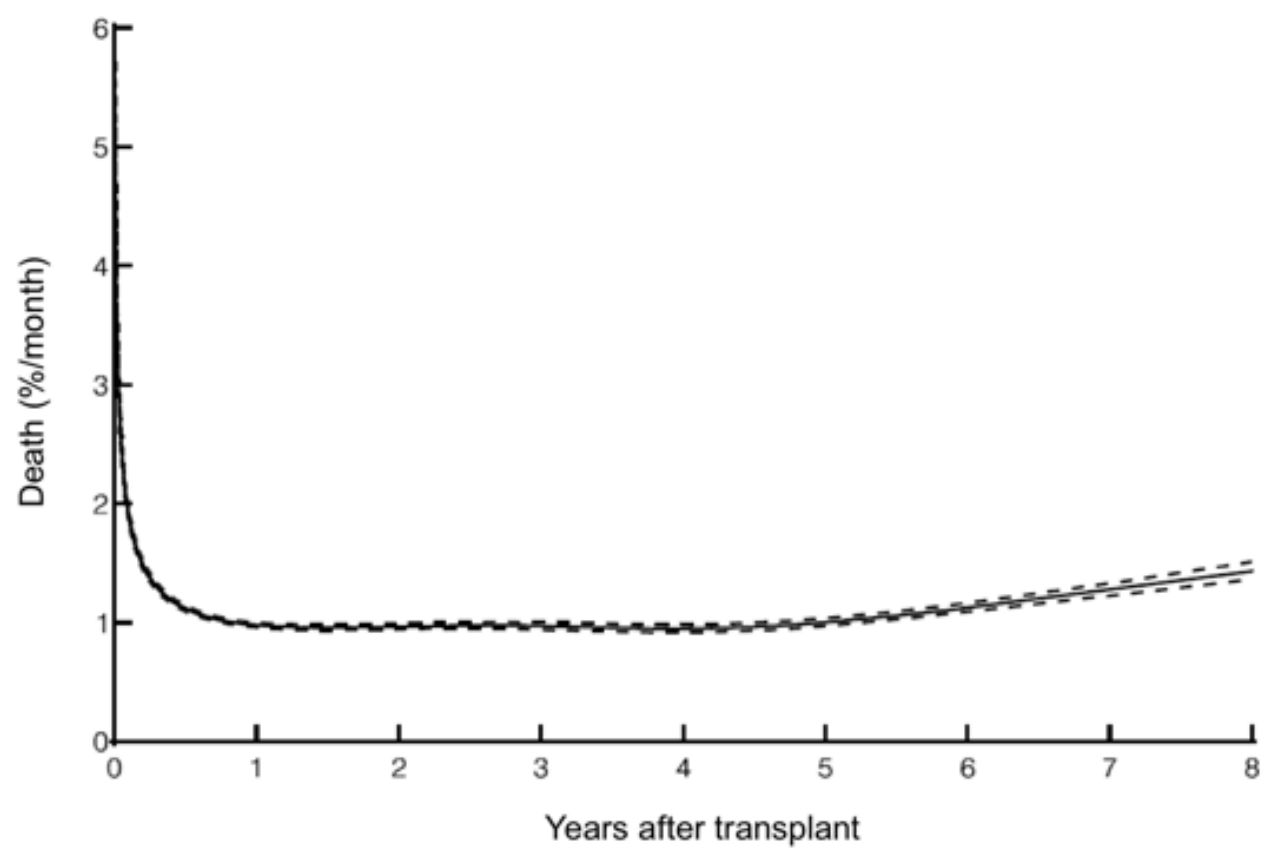

Figure S5: Variable importance measure (VIMP) for death ranked in decreasing order (all ages) 


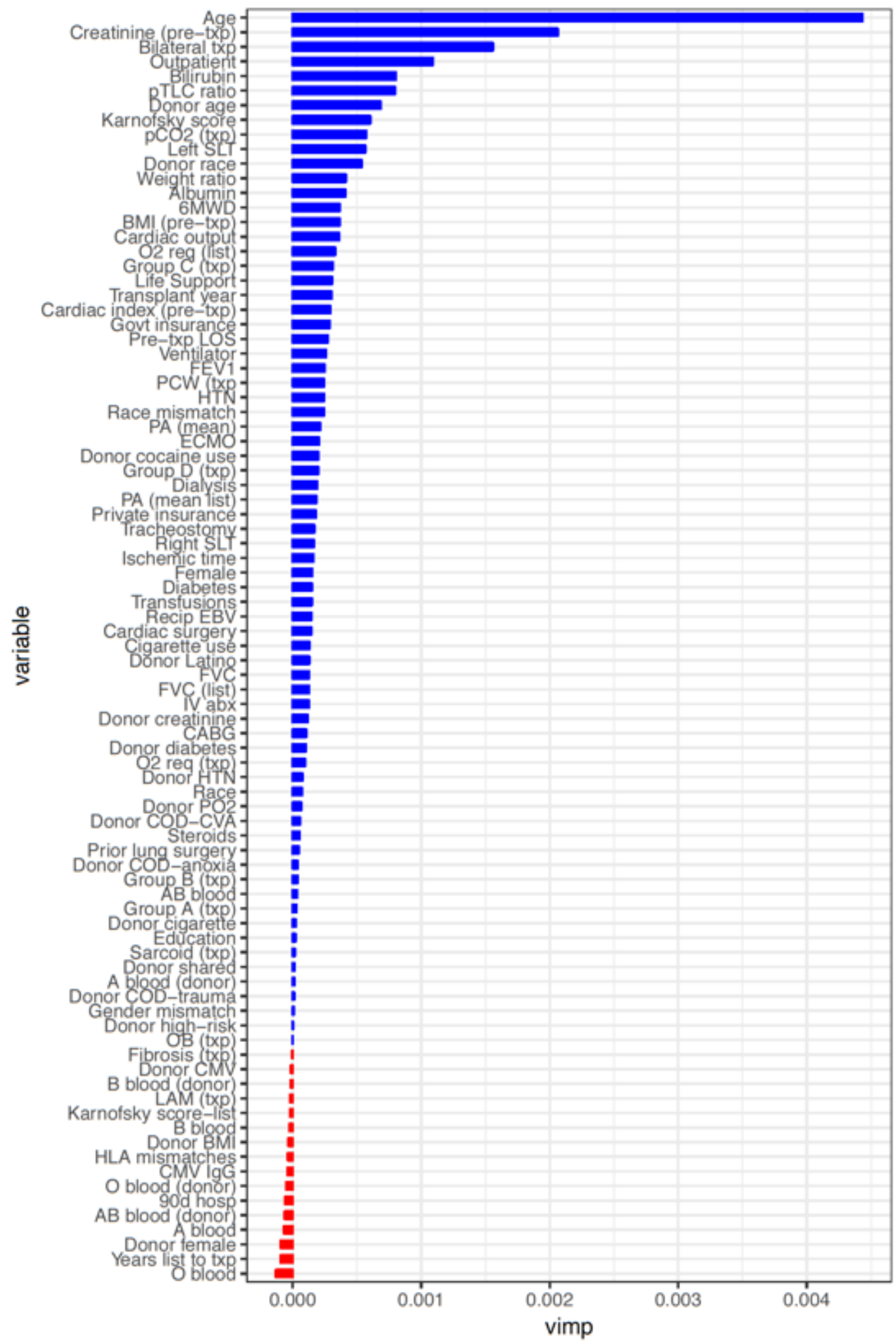


Figure S6: Variable importance measure (VIMP) for death ranked in decreasing order (group: $<30$ years of age)

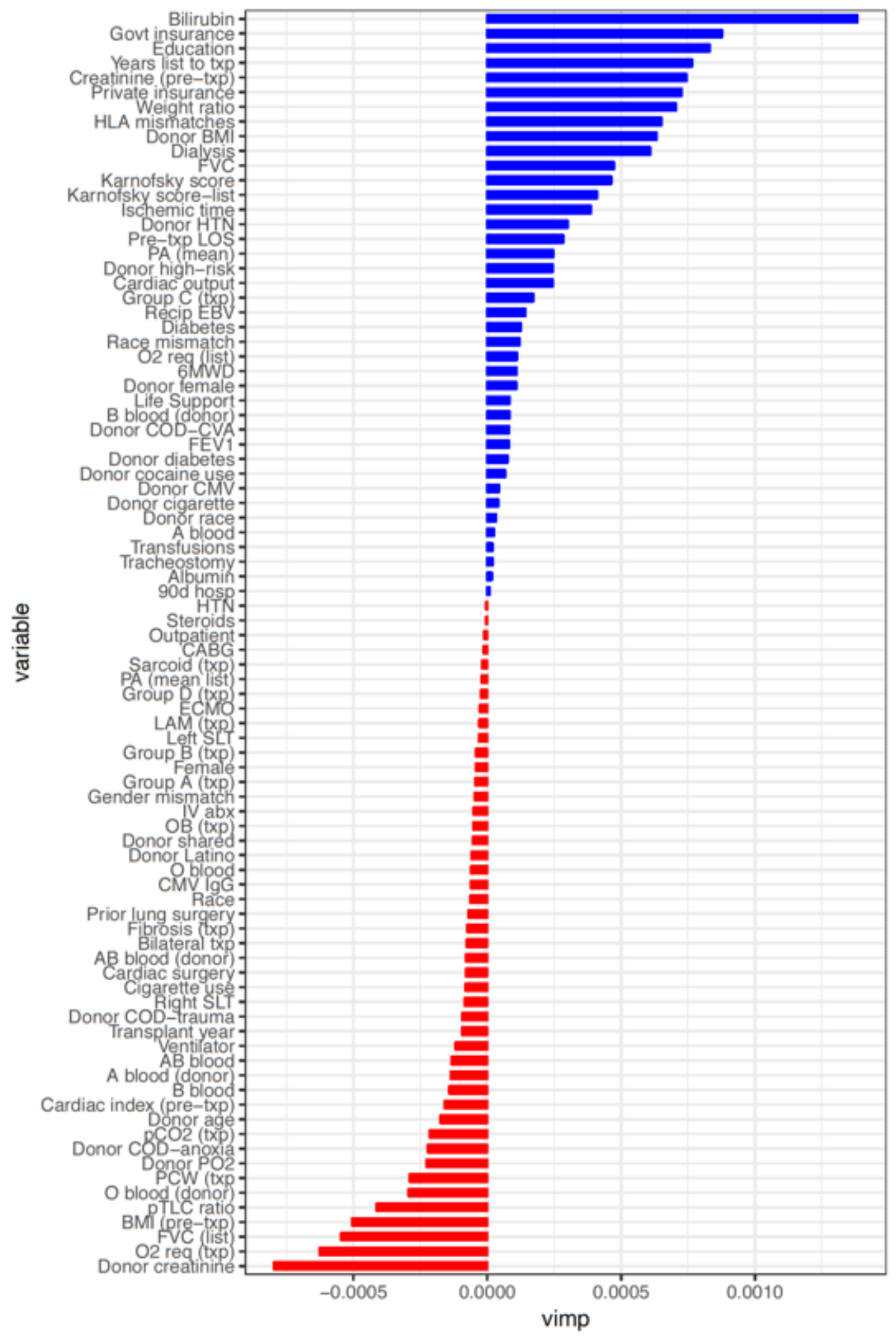


Figure S7: Variable importance measure (VIMP) for death ranked in decreasing order (group: 30 - 55 years of age)

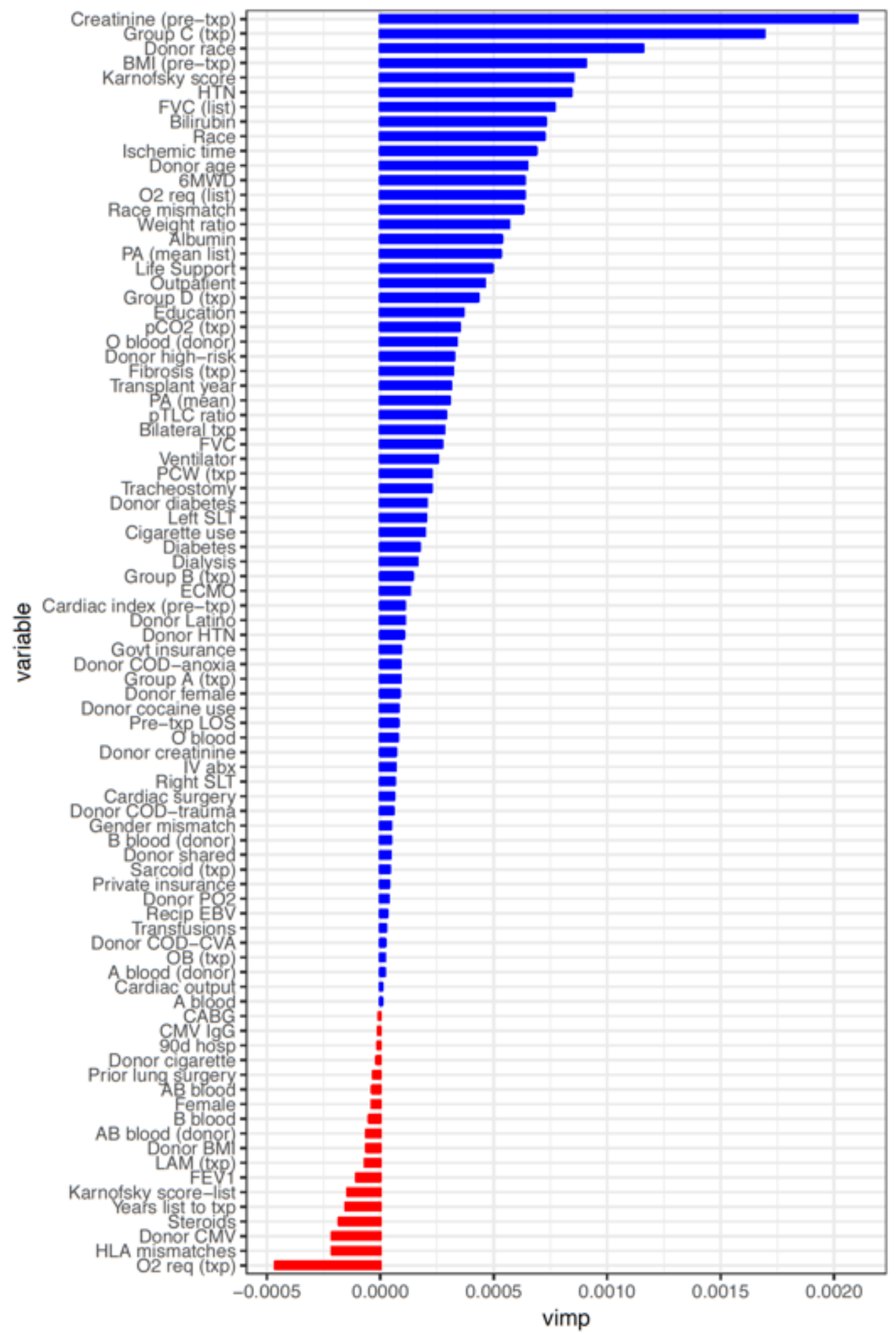


Figure S8: Variable importance measure (VIMP) for death ranked in decreasing order (group: $>55$ years of age)

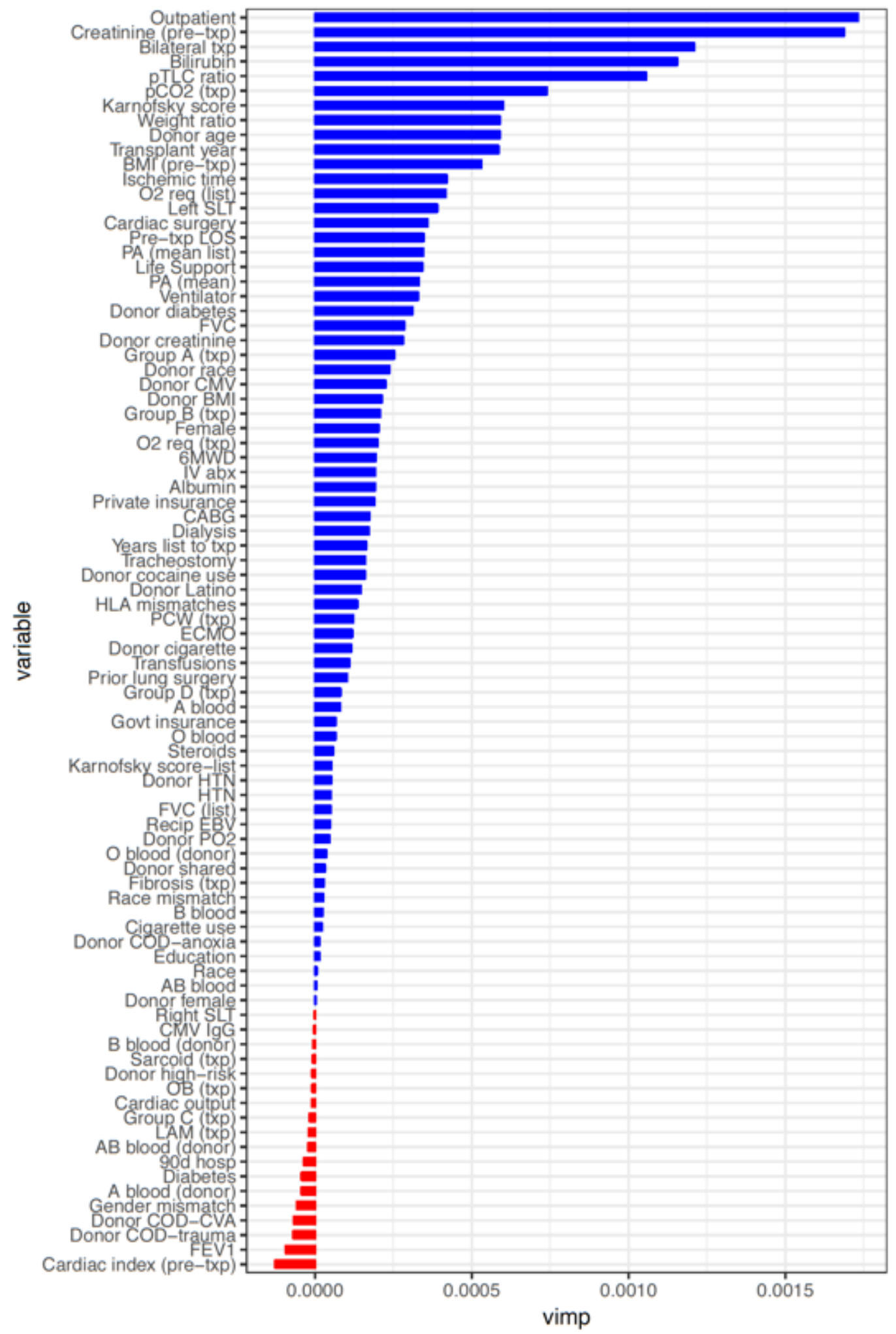


Supplementary Appendix 1: Variables considered in multivariable analyses

\section{a) Recipient}

Demographics: Age, sex, height, weight, weight/height ratio, body surface area, body mass index, race, education, insurance

Blood type: Type A, AB, B, O

Diagnosis: Obstructive disease (group A), pulmonary vascular disease (group B), cystic fibrosis \& immunodeficiency (group C), restrictive lung disease (group D)

Medical/surgical history: Prior lung surgery (non-transplant), diabetes, cigarette use, infection, hypertension, steroid use

Functional status: Karnofsky score (able, unable, disabled)

Serology: Cytomegalovirus (CMV) IgG, Epstein-Barr Virus (EBV) status

Laboratory chemistries: Albumin, creatinine clearance, creatinine, glomerular filtration rate, total bilirubin

Blood pressure: Systolic blood pressure, diastolic blood pressure, mean blood pressure

Hemodynamic data: Pulmonary artery systolic, diastolic and mean pressure, cardiac output, cardiac index, pulmonary capillary wedge pressure

Respiratory \& lung function: Forced expiratory volume in 1 second \% predicted (FEV1), forced vital capacity \% predicted (FVC), carbon dioxide $\left(\mathrm{pCO}_{2}\right)$, oxygen requirement, walk distance in feet

Hospitalization: Hospitalized, ICU, non-ICU, hospitalized within 90 days of transplant, length of pre-transplant hospital stay

Surgical: Double/single transplant, ischemic time

Time: Year of transplantation

\section{b) Donor}

Demographics: Age, sex, height, weight, weight/height ratio, body surface area, body mass index, race

Blood type: Type A, AB, B, O 
Past history: Cigarette use, cocaine use, hypertension, CMV, high risk, organ share, creatinine, lung $\mathrm{pO}_{2}$ on $\mathrm{FiO}_{2}$

\section{c) Recipient donor match}

Size: Ratio recipient weight/donor weight, ratio of donor/recipient predicted lung capacity (pTLC)

Mismatch: Sex, race, human leukocyte antigen (HLA) 
Supplementary Appendix S2: Figure 2 model inputs

Figure 2 represents a nomogram of the Table $2 \mathrm{a}$ model inputs with the following variable values: $\mathrm{BMI}=25$, no pulmonary disease, sero-positive $\mathrm{CMV} \mathrm{IgG}$, no prior cardiac surgery, no dialysis, no hypertension, albumin $=4 \mathrm{~g} / \mathrm{dL}$, creatinine $=0.8 \mathrm{mg} / \mathrm{dL}$, total bilirubin $=0.5 \mathrm{mg} / \mathrm{dL}$, cardiac output $=5.2, \mathrm{FVC}=46 \%, \mathrm{PCO}_{2}=45$, walk distance $=820$ feet, no ventilation, functional status $\mathrm{KS}>50 \%$, non-hospitalized, preop hospital stay=3.5days, waitlist time $=6$ months, ischemic time $=300$ minutes, college education, no sarcoidosis, private insurance, double transplant, right lung, donor age $=35$, donor race white, donor $\mathrm{BMI}=25$, donor sero-positive $\mathrm{CMV}$, recipient/donor weight ratio=1, HLA mismatches $\leq$ 3 , transplant year 2011 
Supplementary Appendix S3: Variable transformations for Table 2 (a-s)
a. $[(\text { Age } / 50)]^{2}$ : squared transformation
b. $[(50 / \text { Age })]^{2}$ : inverse squared transformation
c. $[(25 / \mathrm{BMI})]$ : inverse transformation
d. $[\log (\mathrm{BMI})]$ : logarithmic transformation
e. $[\log ($ Creatinine $)]:$ logarithmic transformation
f. [(1/Creatinine $)]$ : inverse transformation
g. $[(1 / \text { Cardiac output })]^{2}$ : inverse squared transformation
h. [(45/FVC)]: inverse transformation
i. $\left[\left(\mathrm{PCO}_{2}\right)\right]^{2}$ : squared transformation
j. [Log(Walk distance)]: logarithmic transformation
k. [Log(Preop hospital stay)]: logarithmic transformation
1. [Log(Wait time)]: logarithmic transformation
m. [(Ischemic/300) $]^{2}$ : squared transformation
n. $[\log ($ Donor BMI) $]:$ logarithmic transformation
o. [(Recipient/Donor weight ratio) $]^{2}$ : squared transformation
p. [EXP(Age/50)]: exponential transformation
q. [Inv(Total bilirubin)]: inverse transformation
r. [(300/Ischemic)]: inverse transformation
s. [ $\log ($ Donor age $)]:$ logarithmic transformation 


\section{REFERENCES}

1. Valapour M, Lehr CJ, Skeans MA, et al. OPTN/SRTR 2016 Annual Data Report: Lung. Am J Transplant. 2018;18:363-433.

2. Yusen RD, Edwards LB, Dipchand AI, et al. The Registry of the International Society for Heart and Lung Transplantation: Thirty-third Adult Lung and HeartLung Transplant Report_-2016; Focus Theme: Primary Diagnostic Indications for Transplant. J Heart Lung Transplant. 2016;35(10):1170-1184.

3. Inci I, Schuurmans M, Ehrsam J, et al. Lung transplantation for emphysema: impact of age on short- and long-term survival. Eur J Cardiothorac Surg. 2015;48(6):906-909.

4. Gutierrez C, Al-Faifi S, Chaparro C, et al. The effect of recipient's age on lung transplant outcome. Am J Transplant. 2007;7(5):1271-1277.

5. Biswas RS, Alarcon D, Walia R, Chapple KM, Bremner RM, Smith MA. Is there an age limit to lung transplantation? Ann Thorac Surg. 2015;100(2):443-451.

6. Tomaszek SC, Fibla JJ, Dierkhising RA, et al. Outcome of lung transplantation in elderly recipients. Eur J Cardiothorac Surg. 2011;39(5):726-731.

7. Vadnerkar A, Toyoda Y, Crespo M, et al. Age-specific complications among lung transplant recipients 60 years and older. J Heart Lung Transplant. $2011 ; 30(3): 273-281$. 
8. Weiss ES, Merlo CA, Shah AS. Impact of advanced age in lung transplantation: an analysis of United Network for Organ Sharing data. J Am Coll Surg. 2009;208(3):400-409.

9. Kilic A, Merlo CA, Conte JV, Shah AS. Lung transplantation in patients 70 years old or older: have outcomes changed after implementation of the lung allocation score? J Thorac Cardiovasc Surg. 2012; 144(5):1133-1138.

10. Leppke S, Leighton T, Zaun D, et al. Scientific Registry of Transplant Recipients: collecting, analyzing, and reporting data on transplantation in the United States. Transplant Rev (Orlando). 2013;27(2):50-56.

11. A Guide to Calculating the Lung Allocation Score. United Network for Organ Sharing. Sharing. https://www.unos.org/wpcontent/uploads/unos/lung_allocation_score.pdf. Accessed April 2018.

12. Egan TM, Murray S, Bustami RT, et al. Development of the new lung allocation system in the United States. Am J Transplant. 2006;6(5 Pt 2):1212-1227.

13. Team RC. R: A Language and Environment for Statistical Computing. 2013. http://www.r-project.org/. Accessed April 2018.

14. Kaplan EL, Meier P. Nonparametric Estimation from Incomplete Observations. $J$ Am Stat Assoc. 1958;53(282):457-481.

15. Ishwaran H, Kogalur UB, Blackstone EH, Lauer MS. Random survival forests. Ann Appl Stat. 2008;2(3):841-860.

16. Breiman L. Random Forests. Mach Learn. 2001;45(1):5-32. 
17. Blackstone E, Naftel D, and Turner M. The decomposition of time-varying hazard into phases, each incorporating a separate stream of concomitant information. $J$ Am Stat Assoc. 1986;81.395:615-524.

18. Ishwaran H KU. Random Forests for Survival, Regression and Classification (RFSRC). 2017. https://cran.r-project.org/package=randomForestSRC. Accessed April 2018.

19. Ishwaran H. Variable importance in binary regression trees and forests. Electron $J$ Stat. 2007;1:519-537.

20. Rubin D. Multiple imputation for nonresponse in surveys. John Wiley Sons. $2004 ; 81$.

21. Tang F, Ishwaran H. Random forest missing data algorithms. Stat Anal Data Min. 2017;10(6):363-377.

22. Karnofsky D, Burchenal J. The Clinical Evaluation of Chemotherapeutic Agents in Cancer. MacLeod C (Ed), Eval Chemother Agents, Columbia Univ Press. $1949 ; 196$.

23. Mahidhara R, Bastani S, Ross DJ, et al. Lung transplantation in older patients? $J$ Thorac Cardiovasc Surg. 2008;135(2):412-420.

24. Hayanga AJ, Aboagye JK, Hayanga HE, et al. Contemporary analysis of early outcomes after lung transplantation in the elderly using a national registry. $J$ Heart Lung Transplant. 2015;34(2):182-188.

25. Palmer SM, Davis RD, Simsir SA, et al. Successful bilateral lung transplant outcomes in recipients 61 years of age and older. Transplantation. 2006;81(6):862-865. 
26. Nwakanma LU, Simpkins CE, Williams JA, et al. Impact of bilateral versus single lung transplantation on survival in recipients 60 years of age and older: analysis of United Network for Organ Sharing database. J Thorac Cardiovasc Surg. 2007;133(2):541-547.

27. Meyer DM, Edwards LB, Torres F, Jessen ME, Novick RJ. Impact of recipient age and procedure type on survival after lung transplantation for pulmonary fibrosis. Ann Thorac Surg. 2005;79(3):950-958.

28. Meyer DM, Edwards LB, Torres F, Jessen ME, Novick RJ. Impact of recipient age and procedure type on survival after lung transplantation for pulmonary fibrosis. Ann Thorac Surg. 2005;79(3):950-958.

29. Schaffer JM, Singh SK, Reitz BA, Zamanian RT, Mallidi HR. Single- vs doublelung transplantation in patients with chronic obstructive pulmonary disease and idiopathic pulmonary fibrosis since the implementation of lung allocation based on medical need. JAMA. 2015;313(9):936-948.

30. Thabut G, Christie JD, Ravaud P, et al. Survival after bilateral versus single lung transplantation for patients with chronic obstructive pulmonary disease: a retrospective analysis of registry data. Lancet. 2008;371(9614):744-751.

31. Yusen RD, Christie JD, Edwards LB, et al. The Registry of the International Society for Heart and Lung Transplantation: Thirtieth Adult Lung and Heart-Lung Transplant Reprot-2013: focus theme: age. J Heart Lung Transplant. 2013;32(10):965-978. 
32. Paraskeva MA, Edwards LB, Levvey B, et al. Outcomes of adolescent recipients after lung transplantation: An analysis of the International Society for Heart and Lung Transplantation Registry. J Heart Lung Transplant. 2018;37(3), 323-331.

33. Stephenson AL, Sykes J, Berthiaume Y, et al. Clinical and demographic factors associated with post-lung transplantation survival in individuals with cystic fibrosis. J Heart Lung Transplant. 2015;34(9):1139-1145.

34. Liou TG, Adler FR, Cox DR, Cahill BC. Lung Transplantation and Survival in Children with Cystic Fibrosis. N Engl J Med. 2008;357(21):2143-2152.

35. Benden C, Edwards LB, Goldfarb SB, Yusen RD, Stehlik J. Age Trends for Cystic Fibrosis Patients Undergoing Lung Transplantation: An Analysis of the ISHLT Thoracic Transplant Registry. J Heart Lung Transplant. 2016;35(4):S70S71.

36. Ethical principles of pediatric organ allocation. Organ Procurement and Transplantation Network. 2015. https://optn.transplant.hrsa.gov/resources/ethics/ethical-principles-of-pediatricorgan-allocation/. Accessed April 2018.

37. Miriam Holman v. United States Department of Health and Human Services (Case 1:17-cv-09041) 2017. https://optn.transplant.hrsa.gov/media/2394/plaintiff_request_for_tro_ 20171119.pdf. Accessed April 2018.

38. Egan TM, Edwards LB. Effect of the lung allocation score on lung transplantation in the United States. J Heart Lung Transplant. 2016;35(4):433-439. 